\title{
30 anos da Educação Infantil na Anped: caminhos da pesquisa
}

\author{
Eloisa Acires Candal Rocha \\ UFSC / CED / NUPEIN
}

Este trabalho pretende apresentar uma revisão da trajetória do GT07 - da Educação da Criança de 0 a 6 anos - no âmbito das reuniões anuais da Associação Nacional de Pesquisa e Pós-Graduação no Brasil (Anped) nos 30 anos de sua existência, como forma de recuperar também os caminhos da pesquisa sobre educação infantil no Brasil, que tem nesse espaço de associação científica uma significativa expressão da produção nacional.

Em estudos anteriores (ROCHA, 1997, 1999), as principais marcas da origem e consolidação desse grupo já foram sistematizadas e apresentadas, permitindo sustentar aqui uma análise do percurso mais recente das pesquisas: suas temáticas, teorias e, em especial, nos limites deste texto, as metodologias privilegiadas, as áreas científicas de base e os cruzamentos disciplinares.

Tomou-se como base para esta síntese do repertório científico apresentado nas reuniões anuais um levantamento do conjunto dos trabalhos apresentados (organizados num banco de dados) por ano, autoria, título, palavras-chave e resumos a partir de 1990, ano em que os textos integrais passaram a ser exigido para a apresentação. ${ }^{1}$ Paralelamente buscou-se recuperar a trajetória do GT a partir da leitura dos relatórios e programas da Anped $_{2}$ de estudos anteriores sobre o percurso da pesquisa em Educação Infantil no Brasil (CAMPOS; HADDAD, 1992; CAMPOS, 1997; FARIA; CAMPOS, 1989; HADDAD; KISHIMOTO, S/D; ROSA, 1986; MALUF, 1985; ROSEMBERG, 1989; KRAMER E LEITE, 1996), da análise de textos integrais publicados em

\footnotetext{
${ }^{1}$ Todos os trabalhos entre 1990 e 1996 foram arquivados pela Professora Zilma Morais de Oliveira (USP$\mathrm{SP}$ ), uma das coordenadoras do Grupo nesse período, que os disponibilizou para este estudo. O acervo (em papel) encontra-se arquivado no NUPEIN-UFSC desde então. Na época não havia a sistemática de apresentação e arquivamento eletrônico em disquete dos textos pela própria Anped, que se iniciou no ano seguinte. Atualmente a apresentação eletrônica dos textos e resumos é feita em CD-ROMs, o que garante acesso e registro mais permanentes da produção científica apresentada nas reuniões.
} 
periódicos entre 1990-1996 (ROCHA, 1999) e, entre 1997-2002 (MORAES, 2005)², bem como, da leitura dos resumos dos trabalhos do período mais recente, de 2002 a 2006, complementada pela busca de informações nos próprios textos e pelo acompanhamento direto das apresentações e debates nas sessões de trabalho durante as reuniões. ${ }^{3}$

\section{As origens e a consolidação do GT07}

Inicialmente cabe destacar que a origem da constituição deste grupo, assim como a da própria Anped, vincula-se a um caráter político que afirma e consolida o compromisso da associação e de seus membros com uma luta pela conquista do direito à educação pública, gratuita e de qualidade para a população brasileira. Sua organização resultou de um esforço conjunto dos recém-criados programas de pós-graduação em Educação no país, com o objetivo de articular a produção de conhecimento sobre a educação com a reflexão e definição das políticas públicas para a educação.

O GT07 inaugurou sua participação no âmbito da Anped em 1981, como expressão do intenso movimento de discussões sobre as políticas sociais e educacionais que marcou aquela década. ${ }^{4}$. Fundado como GT de Educação Pré-escolar, o grupo reuniu pesquisadores e profissionais ligados à formação e aos sistemas de ensino na rede pública, com a intenção de constituir um fórum de discussões e debates dos problemas e políticas da área ${ }^{5}$. Durante os primeiros anos de sua consolidação, entre as discussões que buscavam um reconhecimento da situação da educação infantil nacional, o GT organizou debates internos e reuniões de trabalho tendo em vista a definição de posicionamentos da Anped frente às novas deliberações legais que pautaram todo o cenário político desde o fim dos anos oitenta, em especial até a promulgação da LBD. Definiu-se como foco da luta política do grupo a viabilização de políticas educacionais

\footnotetext{
${ }^{2}$ Para análise desse período foram consideradas ainda as análises e conclusões da dissertação de mestrado de Andréa Moraes (2005), Educação Infantil: uma análise das concepções de criança e de sua educação na produção acadêmica recente (1997-2002).

${ }^{3}$ Outros dois trabalhos apresentados recentemente (ARAÚJO, 2005;...) analisaram alguns temas tratados em diferentes períodos no GT, porém, embora seus resultados não tenham sido incluídos nesta análise da trajetória, foram considerados no conjunto do repertório de pesquisas analisadas até 2006.

${ }^{4}$ Criada em 1978, a Anped só organizou os Grupos de Trabalho em 1981, na 4a Reunião Anual. Antes disso, realizou suas reuniões em torno de temas gerais, vinculados especialmente aos Programas de PósGraduação.

5 Inicialmente foram constituídos os GTs Educação do 1. ${ }^{\circ}$ Grau, Educação do 2. ${ }^{\circ}$ Grau, Educação Superior, Educação Popular, Educação Rural, Educação e Linguagem e Educação Pré-Escolar. Só em 1988 este último grupo passou a denominar-se Educação da criança de 0 a 6 anos, considerada mais abrangente e mais adequada aos direitos constitucionais que acabavam de ser conquistados.
} 
que abrissem caminho para a efetivação dos direito das crianças à educação infantil (ROCHA, 1997). ${ }^{6}$

Contudo, em seus primeiros anos, o GT de Educação Pré-Escolar buscou acompanhar aquela que vinha sendo a idéia geral dos grupos de trabalho, definida em publicação da Anped e referida por Calazans (1995 p. 54); de acordo com ela, os GT's foram pensados tendo em vista a necessidade de se ter.

[...] um espaço onde as questões teórico-metodológicas e os resultados das pesquisas fossem discutidos. Não podia ser um espaço aberto coletivamente, pois isto exigiria uma reunião longa, o que seria impraticável. Era importante ter um espaço para discussão de pesquisas semelhantes, (o que possibilitaria um avanço nas áreas de conhecimento).

As reuniões refletiam em seus debates alguns dos problemas detectados em pesquisas na área, como pode ser constatado no relatório da então coordenadora Prof. ${ }^{\text {a }}$ Maria Malta Campos, que revela uma preocupação com a atuação do GT em relação às finalidades da Anped:

\footnotetext{
A pré-escola é uma área relativamente desprestigiada dentro de todas as áreas de pesquisa em educação, é uma área onde existe apenas um acervo pequeno de trabalhos, sem uma tradição maior. Estes ainda são imaturos em relação à formulação teórica, e a própria metodologia utilizada pode ser criticada sob vários aspectos (CAMPOS apud HADDAD; KISHIMOTO, [1987?], p.1 apud ROCHA, 1997).
}

O início do grupo coincide com o crescimento do tema nos programas de pósgraduação. Gatti (1983, p. 14) identificou que o interesse pela pré-escola foi evidenciado em 10\% dos trabalhos de pós-graduação em Educação no Brasil entre 1978 e 1981. Expressa também aquele que era à época o interesse do movimento internacional da pesquisa sobre a pequena infância e sua educação, uma elaboração recente que aflorara a partir dos anos setenta. (PLAISANCE; RAYNA, 1997)

Como já evidenciei em trabalhos anteriores, no Brasil nesse período predominava nas pesquisas uma preocupação com a criança pré-escolar e seu desenvolvimento, sempre associados à idéia de privação cultural (CAMPUS; HADAD, 1992). Ainda em 1985, um breve estudo sobre periódicos brasileiros identificou 94 artigos sobre o tema pré-escola ou criança pré-escolar entre 1979 e 1984, que

\footnotetext{
${ }^{6}$ Vários documentos e cartas foram produzidos e tiveram influência na formulação das deliberações legais e governamentais. Ver, por exemplo: Anped (Associação Nacional de Pós-graduação e Pesquisa na Educação). Proposta para o Plano Nacional de Educação do GT 07 - Educação da criança de 0 A 6 anos, XX Reunião Anual. Boletim Anped. Caxambu - MG, 1997.
} 
apresentavam centralmente "uma maior compreensão da realidade e necessidades das crianças provenientes de baixa renda, que representa hoje a maioria da população infantil brasileira (MALUF et al., 1985, p.1).

Rosa (1986) também identificou no início dos anos oitenta uma fase de transição marcada pela ruptura com essas premissas, que se pode identificar como uma ampliação do foco das pesquisas com enfoque nas políticas socioeducativas para a infância (nas etapas educativas anteriores ao ensino fundamental obrigatório), oriundas de uma preocupação com o então recente crescimento das redes públicas de creche e pré-escola no país.

Nos final da década de noventa houve uma pequena redução das pesquisas relacionadas às políticas socioeducativas às quais os pesquisadores vinham se dedicando na década anterior, no entanto a dimensão da atuação política dos pesquisadores que tradicionalmente constituíram este GT foi sempre contínua, destacando-se suas contribuições para a elaboração do Plano Nacional de Educação, com a produção de documentos de orientação para a política nacional da área, e o intenso debate crítico sobre os Referenciais Curriculares Nacionais propostos pelo MEC, a respeito dos quais realizou inclusive trabalhos encomendados em 1998.

De forma geral, é possível afirmar que nesse mesmo período a pesquisa sobre a educação infantil consolidou-se a partir de uma dimensão pedagógica articulada às suas dimensões contextuais. Em parte, essa consolidação pauta-se em bases históricas amplamente investigadas no período e representadas no grupo que analisam criticamente a definição das funções sociais e educativas da creche e da pré-escola.

Em estudos anteriores (Rocha, 1999), vimos identificando as perspectivas de consolidação de um campo particular - a que temos denominado Perspectivas de uma Pedagogia da Educação Infantil ou da Infância - que vem se delineando no âmbito do GT na Anped (mas não exclusivamente nesse espaço, na medida em que os trabalhos aqui apresentados passam a representar em alguma medida a produção acadêmica dos programas de pós-graduação), um conjunto de definições conceituais, afirmações e críticas às orientações teóricas de cunho tradicional instituídas na história da pedagogia e, em particular, nos projetos de educação das crianças, tomadas como indivíduos isolados - meros objetos da intervenção educativa. 
Portanto, a identificação desta perspectiva baseia-se, sobretudo no reconhecimento de uma especificidade da educação da pequena infância, num movimento que busca bases teóricas alicerçadas especialmente na afirmação da infância como categoria histórico-social e na atenção às determinações materiais e culturais que as constituem.

Vale ainda lembrar que, nesse movimento de afirmação teórica, os conceitos de jogo e brincadeira relacionados à linguagem, à construção do conhecimento e aos processos gerais de desenvolvimento da criança são definidos inicialmente e em especial sob o ponto de vista da psicologia histórico-cultural (até então denominada predominantemente pelos autores como perspectiva sócio-histórica), indicando o jogo como eixo da prática pedagógica na educação infantil. ${ }^{7}$ De forma mais ampla, pautadas, sobretudo, numa perspectiva crítica à imposição de modelos ou aos modelos de escolarização tradicionais (conservador e novo), e à centralidade da dimensão cognitiva. Afirma-se a função educativa, traduzida a partir de indicações comuns sob os eixos norteadores da ação pedagógica na educação infantil, associada às interações sociais, à cultura, ao jogo e às diferentes linguagens, experiências e formas de expressão tomadas como base da apropriação do conhecimento; a elas se aliam alguns estudos da linguagem - numa perspectiva teórica que reafirma a natureza social e dialógica da produção e apropriação de significados.

Nesse caminho, assistimos à afirmação de perspectivas teóricas alicerçadas nas determinações socioculturais para a compreensão das relações educativas na infância, acompanhadas da indicação da necessidade de maior atenção às manifestações das crianças e de sua cultura, marcadas por uma inserção concreta e histórica contingenciada pelas relações de classe social, gênero, etnia e raça.

Indica-se assim, no âmbito da pesquisa representada no GT, a especificidade da educação da pequena infância e a insuficiência de metodologias convencionais de pesquisa para o estudo das crianças, da infância e de sua educação. Nesse campo, passase a exigir um alargamento das pesquisas para além dos estudos que tomam como fonte privilegiada, sobretudo as profissionais, as famílias ou os processos pedagógicos, e que dão pouca atenção às relações educativas estabelecidas com as crianças.

\footnotetext{
${ }^{7}$ Esta denominação, até o início dos anos noventa, foi utilizada pelos autores para diferenciar-se da perspectiva interacionista / construtivista representada por Piaget. Os teóricos de referência citados nesta linha de estudos são Vygotsky, Luria, Leontiev, e também Wallon.
} 
Por outro lado, essa exigência se baseia na admissão do desconhecimento sobre as crianças "concretas" e seus modos de viver a infância em contextos coletivos de educação. Indica-se no GT, de forma cada vez mais contundente, a necessidade de estabelecer de um diálogo disciplinar para dar conta de compreender mais amplamente essas relações educativas. Mantém-se neste sentido, nos debates que se segue às reuniões a cada ano, uma vigilância crítica para combater o conhecimento da criança tomado pela perspectiva de isolamento do indivíduo e pelo estabelecimento de padrões de normalidade que tivessem como conseqüência um padrão de ações pautadas na homogeneização ou em modelos e métodos pedagógicos únicos.

A direção tomada pelo grupo, principalmente a partir da 22. ${ }^{a}$ Reunião anual, foi privilegiar contribuições de áreas de conhecimento que têm a criança e a infância como preocupação e que estiveram pouco representadas ou ausentes da trajetória do GT até então. Propuseram-se, a partir daí, minicursos, sessões especiais e trabalhos encomendados para ampliar o debate a esse respeito. ${ }^{8}$ Ao acolher contribuições de outras áreas, visava-se confrontar e ampliar um conjunto de perspectivas teóricas para o estudo das dimensões estruturais, sociais e culturais da educação da infância, no âmbito da educação infantil. Assim, foram convidados pesquisadores da Educação, da Antropologia e da Etnografia, da Filosofia, das Arte e da Estética, da Comunicação e Mídia ${ }^{9}$, entre outros já integrantes do grupo, que vieram a fortalecer o debate e indicar novas frentes de estudo e orientações metodológicas.

Nestes últimos dez anos (1997-2006), intensificou-se a apresentação de trabalhos que se sustentam numa concepção de infância como categoria social, considerando a criança a partir da sua heterogeneidade, como sujeito social heterogêneo - situada a partir de suas condições sociais e culturais, ou seja, a partir das categorias sociais que a constituem.

Preservadas as diferentes bases teóricas, um mapeamento da recorrência dos aportes citados nos trabalhos apresentados permite afirmar que as indicações teóricas e metodológicas que influenciaram os trabalhos nesse período apontam a necessidade de produzir um conhecimento sobre a criança incorporando suas representações, suas

\footnotetext{
${ }^{8}$ Nesse período realizou-se, por exemplo, uma sessão especial incluindo estudiosos da historia da infância, Moysés Kulhmann; da sociologia da infância, Manuel Sarmento e da psicologia ,Solange J.Souza.

${ }^{9}$ Entre esses convidados podemos citar: Nancy Mangabeira, Walter Cohan, Milton Almeida, Márcia Gobbi e Isabel Leite, Manuela Ferreira, Tulia Musatti, Clarisse Cohn, Gilka Guiraldello e João Francisco Duarte.
} 
expressões e significações as dimensões discursivas que a constituem e estabelecendo cruzamentos entre diferentes áreas científicas. Freqüentemente o referencial teórico das pesquisas apresentadas associa autores clássicos de referência a autores contemporâneos e a estudos nacionais recentes, e raramente toma um único autor de forma exclusiva.

Os trabalhos apresentados tiveram como base predominante a Psicologia histórico-cultural já citada, a Filosofia (FOUCAULT, DELEUZE, etc.) - sobretudo nos estudos culturais com foco na infância como sujeito/objeto cultural e nas representações do sujeito infantil -, os estudos da Linguagem e a Filosofia da linguagem (BAKTHIN) - em diferentes bases sociológicas e antropológicas (desde MEAD, GEERTZ, etc.), que se referem à cultura e ao conhecimento das diferenças -, e a Sociologia, em particular a Sociologia da Infância (desde FLORESTAN FERNANDES aos contemporâneos BECCHI, PROUT, SARMENTO, etc.) - quanto à afirmação dos direitos das crianças, o reconhecimento da ação social das crianças e, especialmente, à reafirmação do conceito de cultura infantil, cultura essa não compreendida num sentido absoluto, autônomo ou independente em relação às configurações estruturais e simbólicas do mundo adulto, nem tampouco como mera reprodução.

À afirmação da criança como sujeito social de direitos, que orientou até então as perspectivas de estudo na dimensão das políticas, acrescentam-se pesquisas que assumem o pressuposto da ação social das crianças (ainda que o conceito de ator social tenha pequena inserção direta nos textos), reprodutoras e produtoras de cultura, admitindo de forma sutil a categoria geracional para a análise das relações educativas.

Com essas bases as pesquisas em educação vão apoiar a afirmação da inteligibilidade das crianças, passando a anunciar a necessidade de consideração, no campo investigativo, de suas culturas e modos próprios de compreender e atuar no mundo. Nessa mesma direção é que se questionam os procedimentos metodológicos utilizados nas pesquisas com as crianças, que devem ser direcionados no sentido de recolher tanto suas vozes, como outros a serem conhecidos (MORAES, 2005).

Admite-se haver um desconhecimento sobre as crianças para além do conhecimento produzido nos moldes tradicionais consolidados pela ciência, e aponta-se para a exigência de dar atenção a investigações (preocupação esta que coincide com o que também vem sendo indicado em outras áreas do estudo da infância), que contemplem duas dimensões: tanto a experiência social, que constrange não somente as crianças, quanto às crianças e suas ações e significações dentro do contexto de 
relações, considerando que elas possuem uma multiplicidade de formas de agir em diferentes contextos sociais e culturais. Nessa direção permanece bastante inicial a apresentação no grupo de trabalhos que tenham como preocupação o estudo com bebês nesses contextos (ROCHA, 2007).

Identificam-se algumas convergências teóricas, explicitadas ou não pelos autores, que apóiam a indicação de metodologias definidas como etnográficas ou do tipo e/ou de inspiração etnográfica ${ }^{10}$, poucas vezes identificadas como interpretativas, mas que privilegiam uma maior permanência no campo para as observações e registros (escritos, fílmicos, fotográficos ou pictóricos) das relações, ações e significações dos sujeitos envolvidos no processo educativo em instituições de educação infantil (raramente noutros espaços sociais).

Esse predomínio representou uma mudança em relação às metodologias preferidas pelos pesquisadores da década anterior - quando havia uma variedade de denominações para definir metodologias chamadas genericamente de qualitativas quase sempre centradas em procedimentos que envolviam questionários, entrevistas, observações e análise de documentos, dirigidos principalmente para os sujeitos-adultos (profissionais, famílias, administradores, etc.).

Num segundo patamar mantêm-se as metodologias pautadas em procedimentos de análise de conteúdo para o estudo de políticas, projetos pedagógicos e produção acadêmica em educação infantil, por meio da análise de documentos e de discursos que privilegiam as narrativas adultas, capturadas principalmente em entrevistas (para identificação de concepções de profissionais, famílias e gestores). Outras pesquisas se definem pela simultaneidade da ação/intervenção no processo investigativo quando o foco são os processos/metodologias pedagógicas (envolvendo a brincadeira, a imaginação e outras dimensões expressivas), e poucos trabalhos apresentam-se como ensaios teóricos.

O fortalecimento, mas não a hegemonia das perspectivas que conceituam a criança como sujeito social, reprodutor e produtor de cultura e de história, indicam mais recentemente e de forma tênue uma compreensão diferenciada da participação das crianças no processo educacional, com base na afirmação de sua atuação social e de seu

\footnotetext{
${ }^{10}$ Entre 1997 e 2006 houve um crescimento da etnografia indicada como metodologia, em estudos que tiveram uma grande diversidade de referenciais teóricos (materialismo histórico, estudos culturais, escola de Frankfurt, e nas diferentes perspectivas teóricas da antropologia e da sociologia da infância).
} 
papel ativo nas relações sociais e na apropriação do conhecimento. Destacam-se aqui, no âmbito da educação, as referências à pedagogia consolidada nas experiências originadas nos movimentos político-feministas do norte da Itália, que deram ênfase às capacidades relacionais e comunicacionais da criança pequena na relação entre elas e os adultos no jogo e na elaboração de histórias e significados.

Um conjunto significativo de trabalhos nesta última década situa a infância entendida na sua alteridade e na sua ação inteligível na sociedade, compreendendo necessária à escuta de seus representantes diretos - as crianças. Indica-se assim uma ruptura e uma reconstrução de conceitos relativos ao papel social das crianças na sua própria educação, posição esta representada por um significativo número de trabalhos que afirmam que as crianças, inseridas numa determinada cultura, apropriam-se dela na mesma medida em que contribuem para a sua produção.

Assume-se assim uma contraposição as perspectiva clássicas tradicionais da socialização das crianças - quando são definidas como receptores passivos da cultura -, que em certa medida são reforçadas por uma concepção naturalista do desenvolvimento humano, em que prevalece a perspectiva de constituição da infância como modelagem, como reflexo de uma natureza biológica e natural. Em oposição, a maior importância dada ao papel da cultura - marcada por uma concepção culturalista das relações sociais da criança -abriu caminho para sua própria superação à medida que se passou a reconhecer, sobretudo na Sociologia, a ação social das crianças, que admite não só que os significados são socialmente transmitidos, mas também que são elaborados e transformados pela ação humana.

Desse modo, passa-se a privilegiar procedimentos metodológicos que capturem as diferentes expressões infantis, contrariando a lógica comunicacional adultocentrada, para possibilitar uma relação mais comunicativa e um desafiador processo de aproximação com os diferentes grupos infantis. A brincadeira e a cultura são aqui tomadas como foco para compreender esses processos e as diferentes formas de ser criança e de viver a infância nos contextos de educação coletiva, apresentando desdobramentos para práticas pedagógicas e dando prosseguimento à constituição de um campo pedagógico da infância (ROCHA, 1999).

De forma mais estrita, mas não menos significativos alguns estudos que se diferenciam por suas bases epistemológicas sustentam-se em Gaston Bachelard para definir o sujeito-criança como ser inventivo, ser criador - que se confronta com a 
materialidade e a imaginação criadora na possibilidade de transformar a si e ao mundo; e outros, a partir de Gilles Deleuze, tomam o termo devir-criança como a possibilidade de invenção e criação do mundo para além do aprisionamento e da conformação.

As pesquisas com menor incidência no período recente tomam a criança em desenvolvimento sob uma perspectiva psicológica de observação de um sujeito-objeto que tem seus comportamentos regulados como forma de identificar faltas e etapas a concluir num processo entendido como de maturação e desenvolvimento de capacidades. A educação que se inscreve a partir daí situa a criança como passiva numa relação unilateral determinada pelo professor, que estimula o processo de maturação da criança e a aquisição de conhecimento.

Destaca-se ainda que as garantias dos direitos sociais do direito à educação das crianças sujeitos de direitos permanecem no horizonte dos estudos sobre as políticas nacionais e internacionais e das lutas pela sua efetivação, sendo mais recentemente associadas à crítica da influência dos organismos internacionais sobre os Estados nacionais e as reformas no campo educacional.

Uma análise geral das áreas científicas mais citadas pelos autores e de sua freqüência indica que, entre 1997 e 2002, há predominância da Filosofia e, em segundo lugar, da própria Educação (um terço dos trabalhos), alterando expressivamente a da Psicologia observado na década anterior. Esse movimento contrapõe-se aquele observado entre 1990-1996, quando se verificou, no total dos trabalhos apresentados, que o cruzamento mais freqüente foi entre Educação e Psicologia, seguido de Educação e História e Educação e Linguagem. Outros cruzamentos menos freqüentes envolveram a Antropologia, as Artes, o Serviço Social, as Ciências Políticas, a Comunicação e a Arquitetura, algumas vezes, inclusive, sem incluir a área da Educação. Sem dúvida a maior incidência de trabalhos foi na área da Educação, sem apresentar qualquer outro cruzamento (ROCHA, 1999).

Já nos últimos cinco anos foi expressivo o esforço para o estabelecimento de cruzamentos disciplinares, que passaram a mobilizar esse novo campo, estabelecendo confrontos, disputas e recomposição de consensos nos âmbitos políticos, teóricos, conceituais e mesmo semânticos, na compreensão da infância, das crianças e da educação infantil, marcadas pelas orientações identificadas neste estudo. Observa-se uma expressiva interface entre a Educação e a Sociologia, com presença esporádica das Artes, da Antropologia e da Política, e, em menor número, da 
Arquitetura, da Demografia, da Literatura, do Ensino de Matemática, da Educação Física, da Saúde e da Nutrição.

A identificação das áreas científicas presentes no GT expressa também uma consolidação crescente de algumas disciplinas específicas, particularmente da Filosofia e das Ciências Sociais, que passam a estender sua atenção aos estudos da infância e a abrir possibilidades de interlocução com a educação na infância de forma diferente daquelas trajetórias de estudo desenvolvidas tradicionalmente nas disciplinas específicas voltadas para a educação em geral - é o caso, por exemplo, da Sociologia da Educação, da Filosofia da Educação, etc.

Em recente estudo sobre o panorama das investigações produzidas de 1997 a 2004, do qual resultaram artigos publicados em periódicos educacionais no Brasil, também se constatou que a base disciplinar de apoio ao desenvolvimento das investigações educativas vem estabelecendo cada vez mais cruzamentos teóricos interdisciplinares. A exclusividade do aporte na própria área da Educação permanece quando se estudam a formação dos profissionais, os modelos curriculares e os parâmetros de avaliação de qualidade. Em alguma medida, os temas relacionados à formação, ao direito à educação e à qualidade associam-se a aportes do Direito e das Políticas Públicas.

Destacam-se com maior freqüência os cruzamentos da Educação com a História para sustentar a análise de temas relacionados às origens dos sistemas de suas orientações educativas; com a Sociologia (Sociologia da Educação e, mais recentemente a Sociologia da Infância), inaugurando, por um lado, as preocupações pertinentes à infância e às relações sociais, de gênero e de raça e à exclusão social e, por outro lado, ou associado aos aspectos anteriores, afirmando-se a especificidade geracional e estudando-se as culturas infantis e lúdicas, a televisão e a mídia. Com menor freqüências são identificadas nos periódicos, relações entre a Filosofia e a Educação e entre a Psicologia e a Educação, e, mais recentemente, entre a Saúde e a Educação, esta orientada pela necessidade de compreensão do cuidado como uma das dimensões envolvidas nos espaços coletivos de educação das crianças (ROCHA, 2007). 
Ao longo destes últimos trinta $\operatorname{anos}^{11}$, consolidou-se um novo campo de investigação - que se diferencia dos estudos da educação escolar -, que dá especial atenção ao conjunto das determinações que constituem as relações educativas com crianças - nos espaços educativos formais ou fora deles - e que passa a exigir a contribuição de várias áreas do conhecimento, no sentido de "dar conta" da compreensão dos processos educativos nesse âmbito em suas múltiplas facetas sociais, históricas e culturais. Por outro lado, e considerando a natureza "praxiológica" (no sentido de "o que se pode fazer") do campo educacional, essa compreensão ampliada vem permitindo consolidar indicações metodológicas da ação pedagógica na educação infantil, como já se afirmou noutros estudos, para além da prescrição de modelos. ${ }^{12}$

Percebe-se assim um esforço teórico de análise da educação infantil a partir de uma criança situada social e historicamente. Neste sentido convergem abordagens teóricas que tomam como pressuposto epistemológico um conhecimento da realidade que articula as dimensões estruturais de determinação objetiva à constituição dos sujeitos sociais - sua experiência-ação social que configuram a subjetividade, e que simultaneamente produzem uma dinâmica transformadora.

Para encerrar este texto, mas não as inúmeras possibilidades de análise dessa trajetória, constituída por nós e pela qual também somos constituídas, inspiro-me no poeta Drumonnd e nas companhias/companheiras de luta e de pesquisa, que nele também têm se inspirado para falar da Verdade: se só cabe meia verdade de cada vez, e carece optar, optei também, em certa medida, conforme meu capricho, minha ilusão e minha miopia, mas é isso que mantém aceso um interesse científico, orientado pelo compromisso político de luta contra a exclusão, num permanente estado de indignação!

\footnotetext{
${ }^{11}$ Sobre a trajetória dessas investigações sobre educação infantil na Europa e no Brasil, ver, entre outros: Playsance e Rayna (1997); Neyrand, G. (2000); Campos \& Haddad (1992) e Rocha (1999, 2002, 2007).

${ }^{12}$ Sobre esta reflexão, ver Sacristán (1978).
} 


\section{Referências bibliográficas}

ANPEd (Associação Nacional de Pós-graduação e Pesquisa na Educação). Proposta para o Plano Nacional de Educação do GT 07 - Educação da criança de 0 A 6 anos, XX Reunião Anual. Boletim Anped. Caxambu - MG, 1997.

ARAÚJO, Ana La. Castilhano de. O G.T. 7 da Anped: direitos e educação da criança pequena. Pôster. CDROM da $28^{a}$. Reunião Anual. Caxambu-MG, 2005.

CAMPOS, Maria M. Educação Infantil: o debate e a pesquisa. Cadernos de Pesquisa, n.101, p113-127, jul.1997.

CAMPOS, Maria M.; HADDAD, Lenira. Educação infantil: crescendo e aparecendo. Cadernos de Pesquisa, São Paulo, n.80, p.11-20, fev.1992.

CALAZANS, M. Julieta C. ANPEd - Trajetórias da pós-graduação e pesquisa em educação no Brasil. Documentos ANPEd. Belo Horizonte - MG.Set/1995.

CAMPOS, Maria M. Educação Infantil: o debate e a pesquisa. Cadernos de Pesquisa, n.101, jul.1997, p.113-127.

FARIA, Ana Lúcia G; CAMPOS, Ma. M. Financiamento de Políticas Públicas para crianças de 0 a 6 anos. Cadernos ANPEd (nova fase). N.1, 1989.

KISHIMOTO, Tizuko M. A produção do conhecimento na área da Educação Infantil: jogo e representação social da criança. In: Reunião Anual da ANPEd, 16, 1993, Caxambu / MG, mimeo.

KRAMER, Sonia; LEITE, Maria Izabel. Infância: fios e desafios da pesquisa. CAMPINAS SP: Papirus, 1996.

KUHLMANN JR., Moysés. Infância, História e Educação. In: Reunião da ANPEd trabalho apresentado em Sessão Especial: História da Infância e Educação, 20, set.1997, Caxambu.

HADDAD, Lenira; KISHIMOTO, Tizuko M. História do Grupo de trabalho: Educação da criança de 0 a 6 anos. São Paulo, mimeo, s/d.

MALUF, Regina M. (org.); et al. A Pré-escola em periódicos brasileiros no últimos seis anos: mapeamento das pré-escolas das redes municipal e estadual da cidade de São Paulo. Programa de Estudos Pós-Graduados em Psicologia da Educação. EDUC, dezembro, n.6, 1985.

MORAES, Andréa. Educação Infantil: uma análise das concepções de criança e de sua educação na produção acadêmica recente (1997-2002). PPGE-UFSC, Dissertação de Mestrado, 2005.

NEYRAND, G. L'enfant, la mère et la question du père: un bilan critique sur l'évolution des savoirs sur la petite enfance. Paris: Presses Universitaires, 2000. 
PLAISANCE, Éric; RAYNA, Sylvie. L'education préscolaire aujord'hui: réalités, questions et perpectives. Revue Française de Pédagogie. Institut National de Recherche Pédagogique. N.119, p.107-139, abr. -mai.-jun. /1997.

ROCHA, Eloisa A.C. A Pesquisa em Educação Infantil no Brasil: trajetória recente e perspectivas de consolidação de uma pedagogia. Núcleo de Publicações, CED/UFSC, 1999 (Série tese: 2).

- Saberes sobre as crianças e a infância: algumas questões para um debate científico. Texto apresentado no Seminário Educar na Infância: Perspectivas HistóricoSociais Curitiba, Universidade Federal de Paraná - 11-13 de agosto, 2007.

. As pesquisas sobre educação no Brasil; a trajetória da ANPEd (1990-1996).

Pro - posições, Campinas, v. 10, n. 1, p. 54-74, 1999.

Pedagogia da Infância: uma análise de perspectivas interdisciplinares em

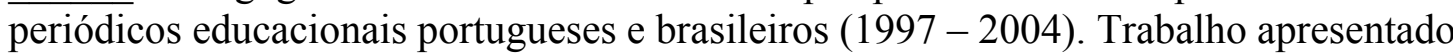
no Congresso da Sociedade Portuguesa de Ciências da Educação, Madeira - Portugal, maio de 2007.

ROSA, Lutero O. A pesquisa sobre educação pré-escolar: uma análise crítica. Revista Brasileira Estudos Pedagógicos. Brasília, 67 (155): 117-34, Jan. /Abr. 1986.

ROSEMBERG, Fúlvia. Educação: para quem? Ciência e Cultura, n.28 (12), dezembro, p $1467-1470,1976$.

. A educação da criança pequena, a produção de conhecimento e a universidade. Cadernos ANPEd. N. 1. 1989.

SACRISTÁN, José. G. Explicación, norma y utopía en las ciencias de la educación. In: Escolano A. e otros. Epistemologia y educación. Salamanca, Ed. Sigueme, 1978.

SANTOS, Solange E. Culturas infantis e saberes: caminhos recompostos. Pôster. CDRom da 28'. Reunião Anual. Caxambu-MG, 2005. 